\title{
Cytochalasin D interferes with contractile actin ring and septum formation in Schizosaccharomyces japonicus var. versatilis
}

\author{
Miroslav Gabriel, ${ }^{1}$ Drahomír Horký, ${ }^{2}$ Augustin Svoboda' \\ and Marie Kopecká1
}

Department of Biology 1 and Department of Histology and Embryology, ${ }^{2}$ Faculty of Medicine, Masaryk University, 66243 Brno, Czech Republic Author for correspondence: Miroslav Gabriel. Tel: +420 542126 266. Fax: +420542126 200.
e-mail: mgabriel@med.muni.cz

The cells of Schizosaccharomyces japonicus var. versatilis responded to the presence of cytochalasin D (CD), an inhibitor of actin polymerization, by the disappearance of contractile actin rings (ARs) that had already formed and by inhibition of new ring formation. Actin cables disappeared. Actin patches remained preserved and became co-localized with regions of actual cell wall formation (at cell poles and at the site of septum development). Removal of the AR arrested formation of the primary septum and led to the production of aberrant septum protrusions in that region. Nuclear division was accomplished in the presence of CD but new ARs were not produced. The wall (septum) material was deposited in the form of a wide band at the inner surface of the lateral cell wall in the cell centre. This layer showed a thin fibrillar structure. The removal of CD resulted in rapid formation of new ARs in the equatorial region of the cells. This implies that the signal for AR localization was not abolished either by CD effects or by removal of an AR already formed. Some of the newly developed ARs showed atypical localization and orientation. In addition, redundant, subcortically situated actin bundles were produced. The removal of CD was quickly followed by the development of primary septa colocalized with ARs. Wall protrusions occurred co-localized with the redundant actin bundles. If these were completed in a circle, redundant septa developed. The AR is a mechanism which, in time and space, triggers cytokinesis by building a septum sequentially dependent on the AR. Aberrant septa were not capable of separating daughter cells. However, non-separated daughter cells subsequently gave rise to normal cells.

Keywords: fission yeast, actin cytoskeleton, actin ring, septum formation, cytochalasin D

\section{INTRODUCTION}

The actin cytoskeleton in fission yeast is known in the form of submembrane actin patches at growing poles and at the site of septum formation, as longitudinally running actin cables, and as actin contractile rings (Marks \& Hyams, 1985; Marks et al., 1986; Kanbe et al., 1989; Alfa \& Hyams, 1990). Longitudinal actin cables have been reported by some authors; in budding yeast, they are regular cytoskeletal components

Abbreviations : AR, actin ring; $C D$, cytochalasin D; DAPI, 4',6-diamidino-2phenylindole dihydrochloride; Rhph, rhodamine-phalloidin.
(Kilmartin \& Adams, 1984; Adams \& Pringle, 1984; reviews by Solomon, 1991; Welch et al., 1994). The actin ring (AR) in fission yeast is related to cytokinesis (Marks \& Hyams, 1985; Marks et al., 1986, 1987; Alfa \& Hyams, 1990; Fankhauser et al., 1995). In addition to actin, at least 15 other proteins have been found, in a number of systems, to localize to the contractile ring or cleavage furrow (Satterwhite \& Pollard, 1992; McCollum et al., 1995).

Cytokinesis in fission yeasts is the result of a sequence of events which starts at metaphase and finishes by separation of two daughter cells (Robinow \& Hyams, 1989; Marks et al., 1992; Fishkind \& Wang, 1995; 


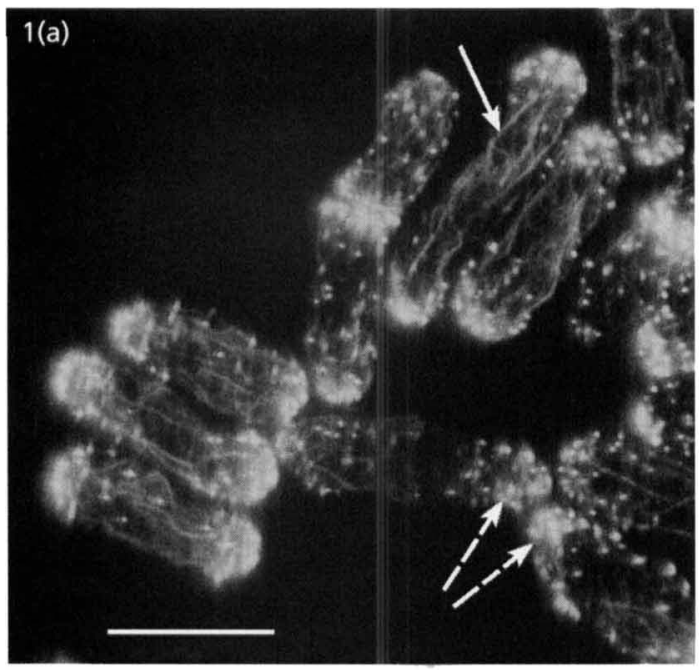

2(a)

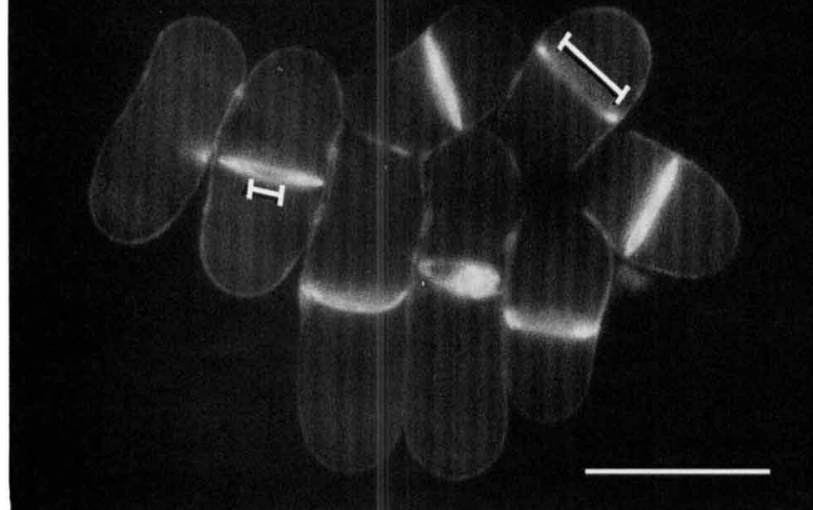

3(a)

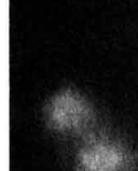

1(b)

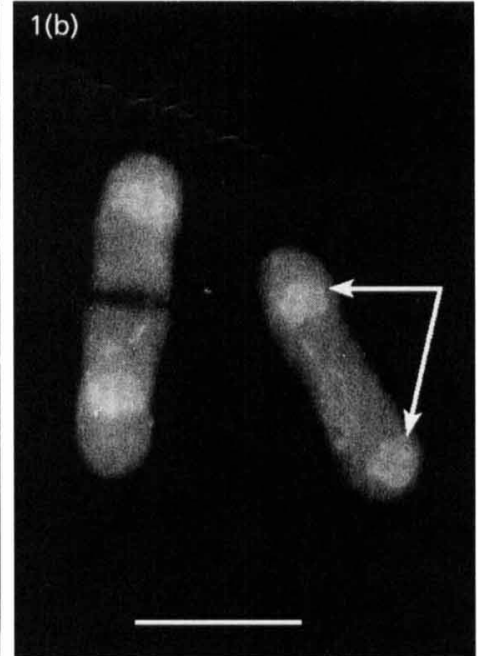

2(b)

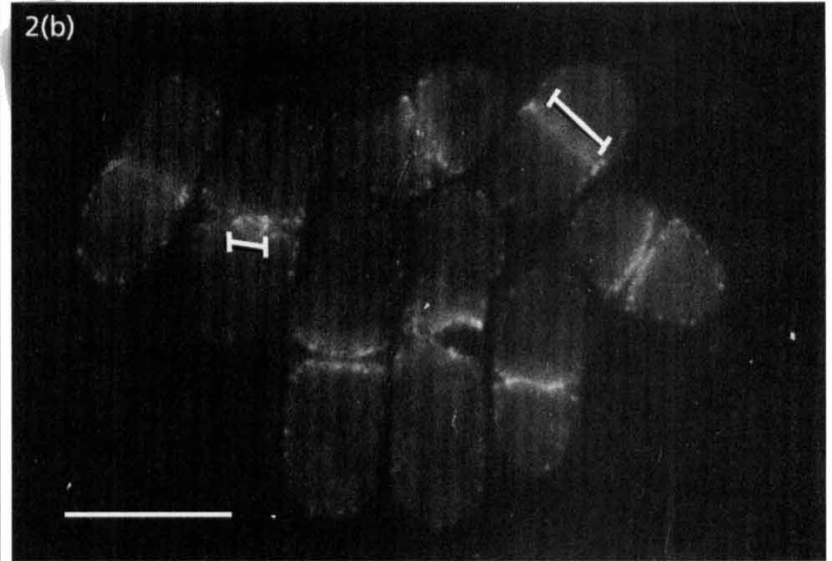

3(b)

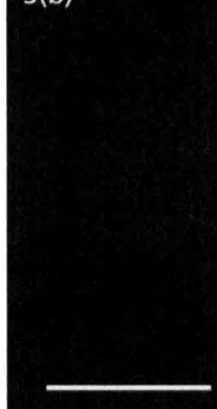

$1(c)$

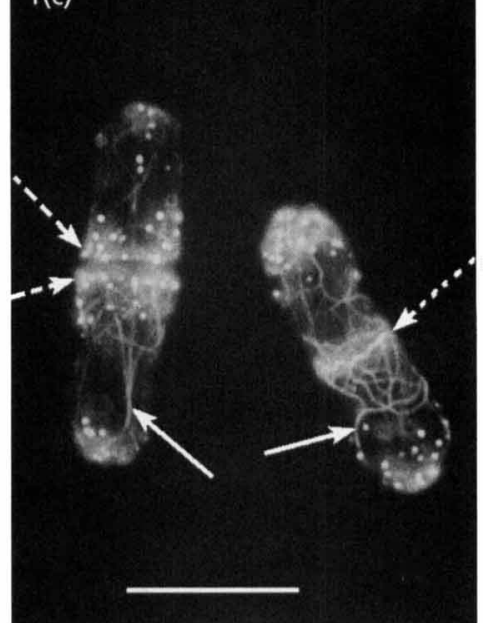

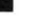


Simanis, 1995; Chang \& Nurse, 1996; Sohrmann et al., 1996; Schmidt et al., 1997). Each of the steps leading from mitosis to cytokinesis has principally been discovered on the basis of blocking one of the events by disruption of the gene responsible, which results in arrested cytokinesis by, among other things, lack of production of the AR. For correct positioning of the AR, the products of the $c d c-15$ (Fankhauser et al., 1995) and $d m f-1 /$ mid-1 genes (Chang et al., 1996; Sohrmann et al., 1996) are necessary. Both proteins appear located at the site of of the future AR. $c d c-12$ encodes a protein that is required for $\mathrm{AR}$ formation. $c d c-12$ mutants exhibit actin patches (dots) instead of an AR and do not form a septum (Chang et al., 1997). The actin gene product itself (Mertins \& Gallwitz, 1987) is also essential for the formation of functional AR (Ishiguro \& Kobayashi, 1996) as well as the actin-associated protein products of $c d c-3$ (profilin), $c d c-8$ (tropomyosin) (Balasubramanian et al., 1992, 1994) and $c d c-4$ (a protein similar to the myosin light chain) (McCollum et al., 1995). Other gene products are necessary for $\mathrm{AR}$ and septum formation, for example plo-1p kinase (Ohkura et al., 1995; Glover et al., 1996). The nuc-2 + gene inhibits septation and cytokinesis until completion of mitosis (Kumada et al., 1995). The product of the $c d c-16$ gene is another link between mitosis and septum formation. The phenotype of $c d c-16$ mutants, in which more septa are started in a cell, indicates the presence of a regulatory control which prevents septation until nuclear division has been completed (Nurse et al., 1976; Minet et al., 1979; Fankhauser et al., 1993). The function of cdc-16p may be to inhibit the septation gene products, and in turn cytokinesis, until the appropriate time in mitosis (McCollum et al., 1996). Cdc-7 protein kinase and Spg1 GTPase regulate septum formation. For septation, activities of cdc-11p and cdc-14p are also required; mutants affected in these genes are defective in transmitting the signal to initiate AR contraction and septation. These mutants are capable of forming an AR, but they do not initiate AR contraction (Nurse et al., 1976; Fankhauser et al., 1993, 1995; Fankhauser \& Simanis, 1994; Simanis, 1995; Sohrmann et al., 1996; Schmidt et al., 1997).

Various papers have reported investigations on septation mutants in fission yeast, but the relationship of the aberrations in these mutants to the actin cytoskeleton was not studied (Streiblová et al., 1984; Mateos \& Domínguez, 1991; Sipiczki et al., 1993). The objective of this study was to investigate the development of septation (cytokinesis) after one of the already formed structures, i.e. the contractile AR, was removed from the sequence of events by cytochalasin D, an inhibitor of actin polymerization (Sampath \& Pollard, 1991). Cytochalasins have already been used several times to inhibit actin polymerization in fungi, e.g. cytochalasin $\mathrm{A}$ in Candida tropicalis (Kobori et al., 1992) and Candida albicans (Akashi et al., 1994) and cytochalasin B in Neurospora crassa (Barja \& Turian, 1994). Cytochalasin A has also been investigated for its effect on actin distribution in Schizosaccharomyces pombe (Kanbe et al., 1993). For this study we chose cytochalasin $\mathrm{D}$ (CD) as did Kobori et al. (1989) for their experiments with $S$. pombe protoplasts.

\section{METHODS}

Strain, media, cultivation and cell fixation. The fission yeast Schizosaccharomyces japonicus var. versatilis, strain CC-60255 , was used in the experiments. Stock cultures were maintained on malt extract agar, $\mathrm{pH} 5 \cdot 5$, at $4{ }^{\circ} \mathrm{C}$. Exponentialphase cells were collected, placed in YEPG medium (Novick \& Botstein, 1985) and incubated at $27^{\circ} \mathrm{C}$ with shaking. Subsequently, cells were fixed for $90 \mathrm{~min}$ directly in the medium, by adding buffered paraformaldehyde to a final concentration of $5 \%(\mathrm{w} / \mathrm{v})$. The phosphate buffer contained $20 \mathrm{mM} \mathrm{MgCl}_{2}$ and $10 \mathrm{mM}$ EGTA (PBS) pH 6.9 (Hašek et al., 1986). In the cells fixed to be stained for actin, the fixation procedure was reduced to $10 \mathrm{~min}$ and was followed by permeabilization with Triton X-100 in PBS. The cells were then washed three times with the buffer $(\mathrm{pH}$ 6.9). All procedures were carried out at room temperature.

Protoplast formation and cultivation. Protoplasts of $S$. japonicus were prepared from exponential-phase cells using lysing enzymes from Trichoderma harzianum (Sigma; $1 \mathrm{mg}$ $\mathrm{ml}^{-1}$ ), in $0.6 \mathrm{M} \mathrm{KCl}$ in citrate/phosphate buffer (pH 5.5). After washing, the protoplasts were cultivated in YEPG medium with mannitol $(0.7 \mathrm{M})$ and $\mathrm{CD}$ (Sigma; $100 \mu \mathrm{g} \mathrm{ml}^{-1}$ ) at $28^{\circ} \mathrm{C}$, or without $\mathrm{CD}$ as a control.

Fluorescence microscopy. Samples were viewed and photographed in a Laborlux S (Leica) fluorescence microscope using an Ilford-PAN 400 film at a primary magnification of $\times 375$.

Nuclear staining. Nuclei to be observed by fluorescence microscopy were stained with 4',6-diamidino-2-phenylindole. $2 \mathrm{HCl}$ (DAPI; Serva Feinbiochemica) at a concentration of $1 \mu \mathrm{g} \mathrm{ml}^{-1}$ in $90 \%(\mathrm{v} / \mathrm{v}$ ) glycerol in PBS, pH 9.0 (Pringle et al., 1989), which was used as a mounting medium.

Rhodamine-phalloidin staining. Actin in fixed cells was visualized using rhodamine-phalloidin (Rhph; Molecular Probes) according to Pringle et al. (1989). A $100 \mu \mathrm{l}$ cell

Fig. 1. Control cells, untreated with CD. (a, c) Staining of the actin cytoskeleton, (Rhph); (b) staining of DNA (DAPI); (b) and (c) show identical double-stained cells. Actin can be seen as actin cables stretched along the longitudinal cell axis (full arrows), as actin patches (dashed arrows) accumulated at growing poles (a), in the area around the developing (secondary?) septum, and as an AR (dotted arrow) (c) appearing after nuclear division (b) (full arrows). Bars, $10 \mu \mathrm{m}$.

Fig. 2. Control cells, untreated with CD. Double staining of walls and septa (calcofluor white) (a) and of actin (Rhph) (b), in identical cells. Centripetally developing septa (a) follow the contraction of ARs (b). The l-bars drawn within two of the cells demonstrate the diameter of contracting ARs $(a, b)$, directing the closure of centripetally developing septa (a). Scale bars, $10 \mu \mathrm{m}$.

Fig. 3. Effect of CD $\left(100 \mu \mathrm{g} \mathrm{ml}^{-1}\right)$ on cells. Staining of nuclei (DAPI) (a, b) and actin (Rhph) (c). (b) and (c) show identical double-stained cells. After treatment with $C D$ for $3 \mathrm{~h}$ or longer, cells were binucleate (a). After nuclear division (b) of growing cells only actin patches on poles and in the central area of cells were detected under the plasma membrane (arrows) (c). No ARs and no actin cables were detected in the presence of CD. Bars, $10 \mu \mathrm{m}$. 
sediment in PBS was mixed with $10 \mu$ l of the original Rhph solution in methanol and allowed to stain for $30-60 \mathrm{~min}$ at room temperature. The cells were washed once with PBS and placed on grease-free slides to dry. The mounting medium with DAPI was then added. All the procedures were performed in a dark room or under red light.

Microtubular staining. The anti-tubulin monoclonal antibody TAT1 (Woods et al., 1989) was applied according to Svoboda et al. (1995). The cell walls of fixed cells were permeabilized using a snail-enzyme solution (based on the digestive juice of Helix pomatia) or lysing enzymes isolated from Trichoderma harzianum (Sigma) for $20 \mathrm{~min}$ at room temperature. This was followed by permeabilization with $1 \%$ Triton X-100 for 5 min. After two washes with PBS, the samples were preincubated for $30 \mathrm{~min}$ in PBS containing bovine serum albumin $(2 \%, v / v)$ at $37^{\circ} \mathrm{C}$ and then TAT1 anti-tubulin antibody was applied for $2 \mathrm{~h}$ at $37^{\circ} \mathrm{C}$. After three 5 min washes with PBS, the secondary antibody SwAM-FITC (Sevac Prague) was applied for $1.5 \mathrm{~h}$ at $37^{\circ} \mathrm{C}$. The process was completed by another three 5 min washes with PBS.

Calcofluor white staining. Calcofluor white (Sigma) was diluted in PBS and this stock solution was added to the fixed cell suspension to achieve a concentration of $50 \mu \mathrm{g} \mathrm{ml}^{-1}$ for cell wall visualization according to Pringle (1991). Preparations were stained for $5 \mathrm{~min}$.

Cytochalasin D (CD) treatment. A stock solution of CD (Sigma) was prepared by dissolving $5 \mathrm{mg} \mathrm{CD}$ in $1 \mathrm{ml}$ DMSO and was kept at $-20^{\circ} \mathrm{C}$. It was subsequently mixed, in $10 \mu \mathrm{l}$ amounts, with appropriate amounts of the cell suspension in YEPG medium to give final concentrations of 25,50 and $100 \mu \mathrm{g} \mathrm{CD} \mathrm{ml}^{-1}$. The cells were treated with CD for 3-5 h, or for $24 \mathrm{~h}$. After removal of CD from the nutrient medium, cells were studied in samples taken every $10 \mathrm{~min}$ for $1 \mathrm{~h}$, and then after 2, 4 and $24 \mathrm{~h}$. The treatment was carried out under red light. A solution of DMSO alone, at the corresponding concentrations, had no effect on control cells.

Electron microscopy. Cells were fixed with glutaraldehyde $(300 \mathrm{mM})$ in cacodylate buffer $(100 \mathrm{mM})$ containing tannic acid $\left(0.2 \mathrm{~g} \mathrm{l}^{-1}\right)$. They were washed three times with cacodylate buffer and postfixed with $\mathrm{OsO}_{4}(20 \mathrm{mM})$ in cacodylate buffer $(100 \mathrm{mM})$. Samples were dehydrated in an alcohol solution, embedded in Durcupan ACN by the standard method and polymerized in an oven at $60^{\circ} \mathrm{C}$ for $3 \mathrm{~d}$. Ultrathin sections were made using an LKB Nova microtome and stained with Reynolds' lead citrate or with a combination of $1 \%$ uranyl acetate and lead citrate. They were viewed and photographed with a Tesla BS 500 electron microscope.

\section{RESULTS}

\section{Actin in control cells}

The distribution of actin was in accordance with the published data on S. japonicus (Alfa \& Hyams, 1990) or in the more commonly used S. pombe (Marks \& Hyams, 1985; Marks et al., 1987; Kanbe et al., 1989); the first signs of the presence of an AR were detected at the moment when the dividing daughter nuclei were situated close to the poles. Actin was detected as patches located at the growing tips and at the site of septum development, as fine actin cables stretching along the longitudinal cell axis, and as ARs in dividing cells. The modified fixation method used made the actin cables easily discernible (Fig. 1a-c).
The combined staining for actin (Rhph) and cell wall structure (calcofluor white) demonstrated that the gradual contraction of the AR was followed by centripetal formation of the primary cell septum (Fig. 2a, b). The developing primary septum showed brighter fluorescence than the lateral cell wall. At the site of this developing septum, a marked rearrangement of actin patches was detectable. These were accumulated on both sides of the forming septum, and they were reduced in amount at the cell poles at this time. During the process of septum closure, a pear-shaped structure was seen in the isthmus but its fluorescence was usually masked by the bright fluorescence of actin patches.

The ultrastructure of cells in ultrathin sections showed the standard distribution of cell organelles. However, the method used failed to contrast membrane structures and the nucleus (Fig. 8). The primary septum grew centripetally out from the lateral cell wall. Along the developing septum, a layer free from ribosomes and showing a filamentous texture was detected (Fig. 7).

\section{Effect of CD}

Cells of $S$. japonicus exposed to $100 \mu \mathrm{g} \mathrm{CD} \mathrm{ml}^{-1}$ grew slowly, usually up to twice their normal length. Nuclear division was not blocked by CD treatment. Cultures grown without $\mathrm{CD}$ had about $18 \%$ of binuclear cells. After $30 \mathrm{~min}$ incubation with CD, the cultures contained about $30 \%$ of binuclear cells, after $60 \mathrm{~min}$ about $70 \%$, and after $90 \mathrm{~min}$ about $90 \%$. After $3 \mathrm{~h}$ incubation with $\mathrm{CD}$, the cultures contained $96 \%$ of binuclear cells (Fig. 3a). Staining with Rhph, however, identified no formation of new ARs (Fig. 3c).

The ARs that were created before applying CD become successively less stained after $C D$ application. In untreated cultures about $17 \%$ of cells with ARs were detected. After $30 \mathrm{~min}$ CD treatment the culture contained about $7 \%$ of cells with ARs; it appeared that the ARs with less bright fluorescence represented a transitional stage. After $60 \mathrm{~min}$ CD treatment, no ARs could be identified in the culture. Whether the effect of CD on the disappearance of ARs was caused by inhibition of polymerization (or even by AR degradation) could not be determined. At this period, however, some unclosed septa, whose formation had started before CD application, were closed and the proportion of cells with closed septa was slightly increased. About $12 \%$ of the cells had the primary septum stained with calcofluor before CD application, but only $6 \%$ of the septa were closed. After $1 \mathrm{~h}$ incubation with $\mathrm{CD}$, the culture contained $10 \%$ of cells with closed septa. Each counted sample contained more than 600 cells and the standard deviation did not exceed $2 \%$ of the mean.

CD did not inhibit the occurrence of actin patches. These were localized either typically at the growing cell poles or, less frequently, in a dense band, along the cell equatorial plane (Fig. 3c).

CD treatment did not influence the microtubular components of the cytoskeleton. During incubation of cells with $\mathrm{CD}$, nuclear division was manifested by readily 

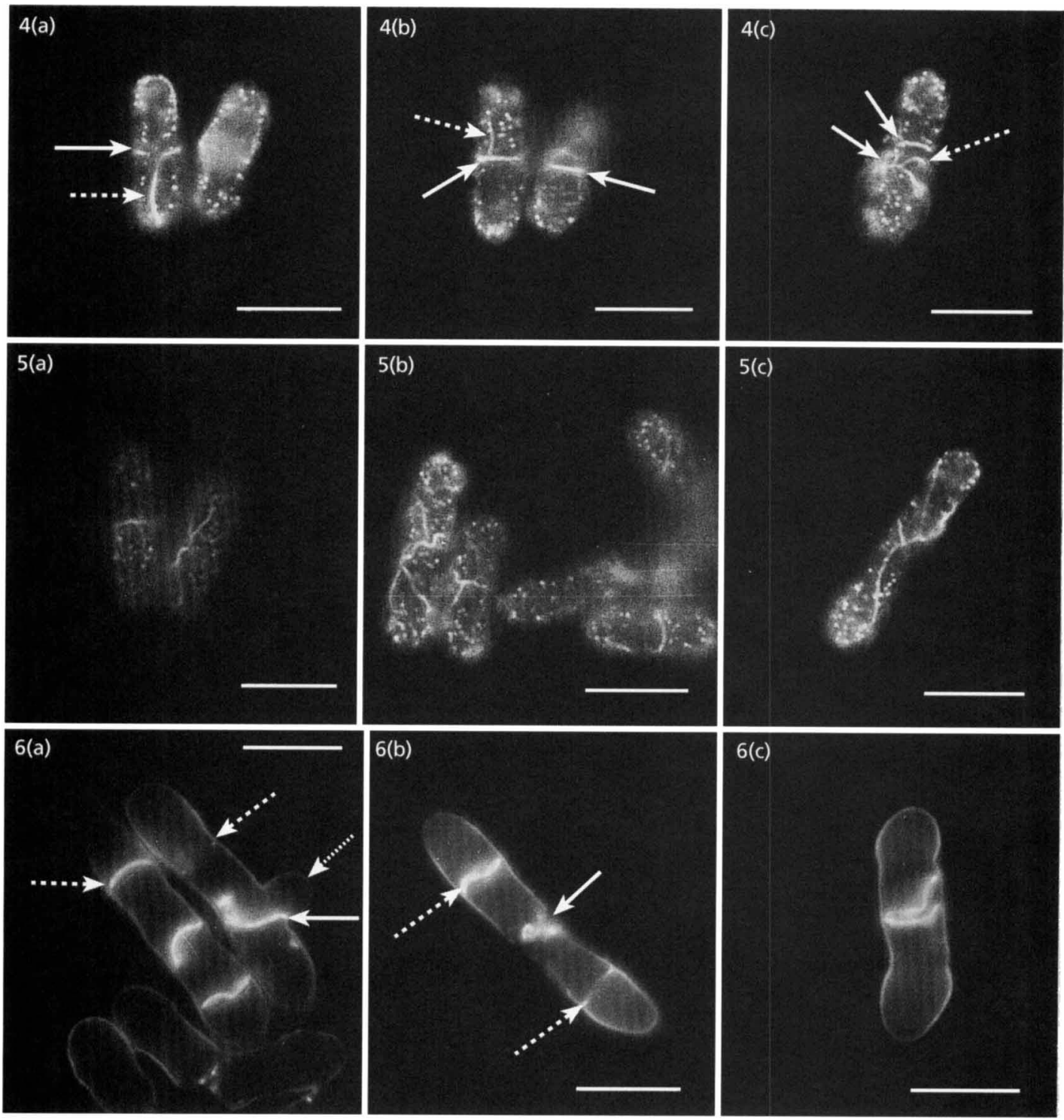

Fig. 4. Effect of removal of $C D$ : staining of actin (Rhph). $(a, b)$ Identical cells at different planes of focus. Ten minutes after removal of $C D$ from nutrient medium, ARs reappeared under the plasma membrane (full arrows). They were localized in the equatorial plane of the cell $(a, b)$; however, multiple ARs were also formed (c). Redundant subcortical actin bundles, forked from ARs, also frequently appeared (dashed arrows) (a, b, c). Bars, $10 \mu \mathrm{m}$.

Fig. 5. Effect of removal of $C D$ : staining of actin (Rhph). After removal of $C D$, frequent redundant actin bundles were detected under the plasma membrane. They were either joined to the AR (see Fig. 4) or were randomly distributed (a, b); sometimes they were even oriented along the longitudinal cell axis (c). They mostly disappeared during 60 min following CD removal. They frequently co-localized with aberrant wall protrusions (not shown). Bars, $10 \mu \mathrm{m}$.

Fig. 6. Effect of removal of $C D$ : staining of walls and septa (calcofluor white). When CD was removed, thick, often aberrant septa were formed in the area of reappearance of ARs that divided the cell but did not separate it (full arrows) $(a, b)$. In growing daughter cells formed after removal of $C D$, normal new septa originated (dashed arrows). Aberrant septa sometimes deviated from the axis of the polar growth of new daughter cells (dotted arrow) (a). Double and multiple aberrant septa (c) were found that coincided with the presence of double and multiple ARs. Bars, $10 \mu \mathrm{m}$.

discernible nuclear microtubular spindles. Cells exposed to $C D$ for $3 \mathrm{~h}$ or longer had increased amounts of cytoplasmatic microtubules (not shown).

\section{Cell wall changes}

Electron microscopy revealed that, in the presence of $\mathrm{CD}$, some aberrant septum (wall) material accumulated in the equatorial plane of binuclear cells (at the site of expected septum formation). This material was deposited in a wide band between the plasma membrane and the original lateral cell wall (Fig. 9).

In cells in which the process of septation started before CD application, further normal septum organization was blocked. In this area, aberrant septum (wall) 

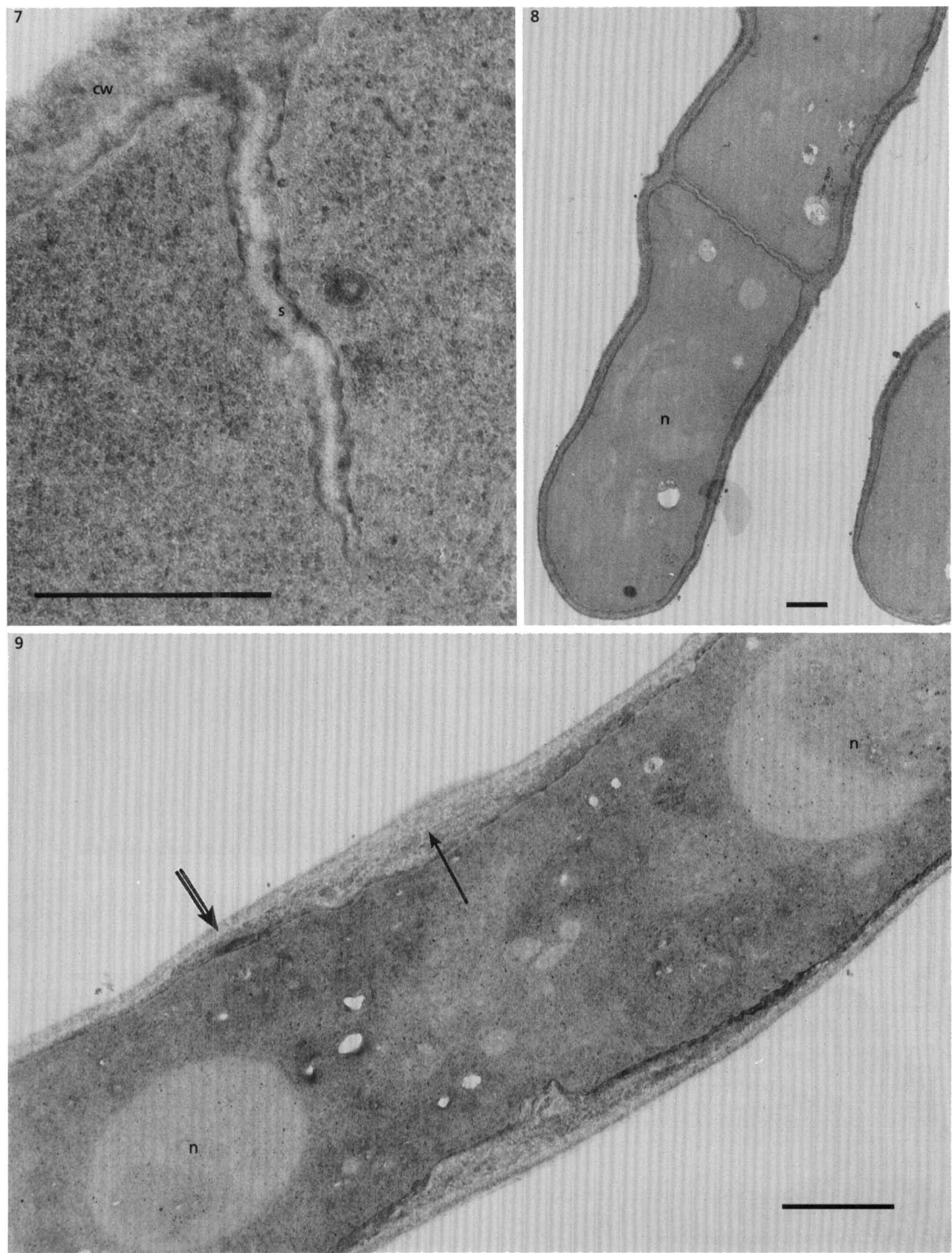

Figs 7, 8 and 9. For legends see facing page. 
material produced protrusions of varying sizes (Fig. 10) which lacked proper spatial orientation and did not have the typical appearance of a septum. This material was aggregated in various locations along the cell circumference but it failed to form a regular circular structure.

When the cultivation of cells in CD lasted $24 \mathrm{~h}$, septation of cells with a mass of aberrant wall material was often found (Fig. 11).

\section{Repair of the AR and septum development after removal of $C D$}

After $C D$ was removed by washing the culture with nutrient medium, the formation of ARs in binuclear cells occurred rapidly. The new ARs were detected by fluorescence microscopy 5-10 min later. Within 20-30 min, more than $70 \%$ of the population possessed ARs. Moreover, electron microscopy of cells 10 min after CD removal revealed incipient primary septa (Figs 13 and 14). Eventually, all binuclear cells contained ARs or primary septa.

In most cases, the AR was localized close to the cell equator, i.e. at its usual site in unaffected cells (Fig. 4a, b). However, the perpendicular position of the AR in relation to the long axis of the cell was usually not resumed (about $60 \%$ of cells). Frequently, ARs were duplicated (Fig. 4c) or branched (Fig. 5) (the number of those aberrations varied between experiments - from $5 \%$ to $60 \%$ of cells). These abundant actin bundles were either associated with typical ARs (Fig. 4a, b) or were independent, and were often chaotically distributed (Fig. 5b, c) (cf. Kanbe et al., 1994). They were all close to the cell surface (plasma membrane). The maximal number of these structures was observed at about $20 \mathrm{~min}$ after removal of $\mathrm{CD}$. At $1 \mathrm{~h}$, only closed ARs or occasional thick actin bundles were found to persist.

In ultrathin sections through cells which were processed within 10 min of CD removal, newly formed primary septa were seen as electron-transparent protrusions resembling plasma membrane invaginations and 'anchored' in a thickened aberrant cell wall layer present in the equatorial region of the cell (Fig. 13). The occurrence of developing septa often coincided with the presence of atypically oriented ARs (Fig. 12).

Cells incubated in nutrient medium for $3 \mathrm{~h}$ or longer after CD removal showed thick septa when observed in ultrathin sections. The electron-transparent layer of the primary septum was preserved and had thick, structurally different layers ('secondary septa') attached to each side. These thick layers continued with the adjacent parts of the lateral wall (see Fig. 14). Such aberrant septa divided binuclear cells into uninuclear compartments, but the daughter cells did not separate (Fig. 6a, c, Fig. 14). These septa were even found to influence the polar growth of cell poles (Fig. 6a). Some of the wall protrusions or lamellae showed a disoriented course, suggesting the loss of controlling mechanisms (closed circular AR) (Fig. 15). Occasional findings indicated that $\mathrm{CD}$ removal may have led to the division of cells into several compartments (Fig. 16).

Divided, but not separated, daughter compartments increased in size. The next nuclear division produced normal septa (Fig. 17) and the cell cycle returned to normal. The following generations did not differ from the original culture of $\mathrm{CD}$-untreated cells.

\section{Effect of CD on protoplasts}

Protoplasts of $S$. japonicus treated with $100 \mu \mathrm{g} \mathrm{CD} \mathrm{ml} l^{-1}$ grew isodiametrically very slowly and they became binucleate. They synthesized a fine fibrillar network only, which did not enable cell wall regeneration. As the protoplasts increased in size they emerged from the fibrillar network, leaving behind a 'ghost' of cell wall material resembling a stocking. As long as they synthesized a fibrillar network, actin patches could be observed after $\mathrm{Rhph}$ staining. Protoplasts in CD remained viable for more than $24 \mathrm{~h}$ (not shown).

\section{DISCUSSION}

Our observations on the actin cytoskeleton, its characteristics and redistribution during the cell cycle, are in agreement with previous findings in S. pombe (Marks \& Hyams, 1985) and S. japonicus (Alfa \& Hyams, 1990). In contrast to $S$. pombe, the first signs of the presence of the AR were observed later in $S$. japonicus. The shortened fixation followed by detergent application used in this study allowed us to achieve clear visualization of actin cables and rings. The microtubule cytoskeleton in the two species was similar (Alfa \& Hyams, 1990; Svoboda et al., 1995; our unpublished results). S. japonicus, like the classical model fission yeast $S$. pombe, divides by medial fission by means of an F-actin contractile ring (AR) (Fishkind \& Wang, 1995). Much of our current understanding of the molecular mechanism which regulates cytokinesis in fission yeasts is derived from the targeted disruption of genes involved in cytokinesis. The use, as in this study, of an inhibitor of a specific protein function models the phenotypic modification, without influencing the relevant gene. CD

Fig. 7. Electron micrograph of an ultrathin section through a control, untreated cell. The primary septum (s) of the cell grows centripetally from the cell wall (cw). An electron-transparent layer, almost free of ribosomes, and having filamentous features, is visible along the electron-transparent septum. Bar, $0.5 \mu \mathrm{m}$.

Fig. 8. Electron micrograph of an ultrathin section through a control, untreated cell. The cell wall and the septum are contrasted, but not the membrane structures or the nucleus $(n)$. Bar, $1 \mu \mathrm{m}$.

Fig. 9. Electron micrograph of an ultrathin section of a cell treated with $C D\left(100 \mu \mathrm{g} \mathrm{ml}^{-1}\right)$ for $4 \mathrm{~h}$. Divided nuclei ( $\mathrm{n}$ ) are already localized in the central area of the future presumed daughter cells, but the septum was not formed. Instead of it, a thickened layer of aberrant, flat wall material (arrow) was formed at the inner side of the wall under the original lateral cell wall (double arrow). Bar, $1 \mu \mathrm{m}$. 


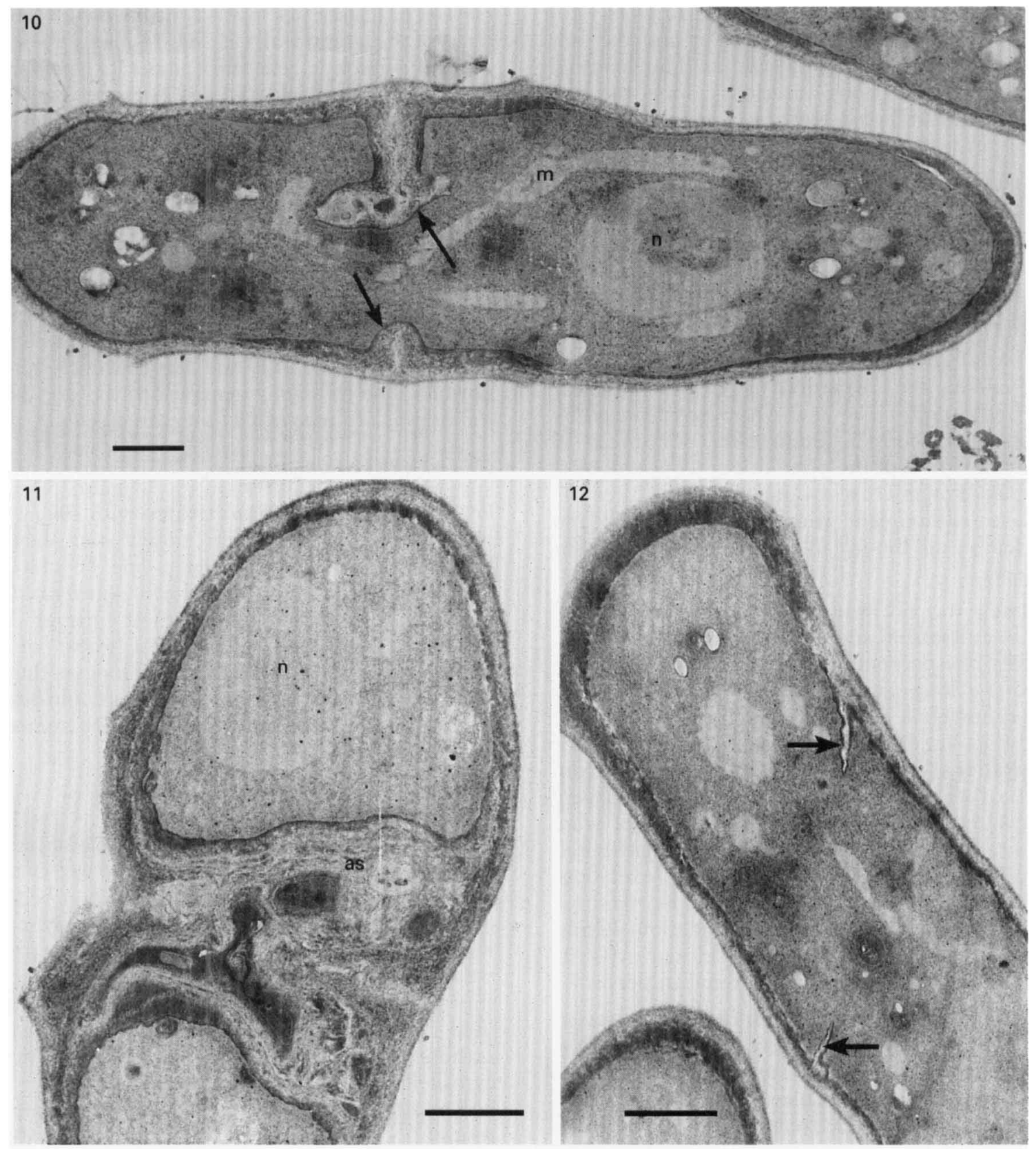

Fig. 10. Electron micrograph of an ultrathin section of a cell treated with $C D$, in which septation was initiated before $C D$ application. The effect of $C D$ on actin caused the septum to become disorientated and fail to complete. Instead, irregular aberrant outgrowths of septum material were formed (arrows). The nucleus ( $n$ ) and mitochondria ( $m$ ) are not contrasted. Bar, $1 \mu \mathrm{m}$.

Fig. 11. Electron micrograph of an ultrathin section of a cell cultivated in the presence of $C D\left(100 \mu \mathrm{g} \mathrm{ml}^{-1}\right)$ for $24 \mathrm{~h}$. CD did not block synthesis of the septum (wall) material, which formed aberrant protrusions that divided the cell into two compartments. $n$, Nucleus; as, aberrant septum material. Bar, $1 \mu \mathrm{m}$.

Fig. 12. Electron micrograph of an ultrathin section of a cell recovered from the effect of $C D$. At 10 min after removal of $C D$, a primary septum was formed. Aberrations in the localization and course of the primary septa (that coincided with the presence of atypically oriented ARs) were frequently found (arrows). Bar, $1 \mu \mathrm{m}$.

blockage of the AR mimics findings with fission yeast mutated in the actin gene (Ishiguro \& Kobayashi, 1996), in actin-associated proteins (Balasubramanian et al., 1992, 1994; McCollum et al., 1995, 1996), and in the organizing signal and localization of the contractile ring
(Ohkura et al., 1995; Fankhauser et al., 1995; Chang \& Nurse, 1996; Sohrmann et al., 1996; Chang et al., 1997).

Localization of the AR seems to involve the protein products of the genes plo-1 (Ohkura et al., 1995), mid- 

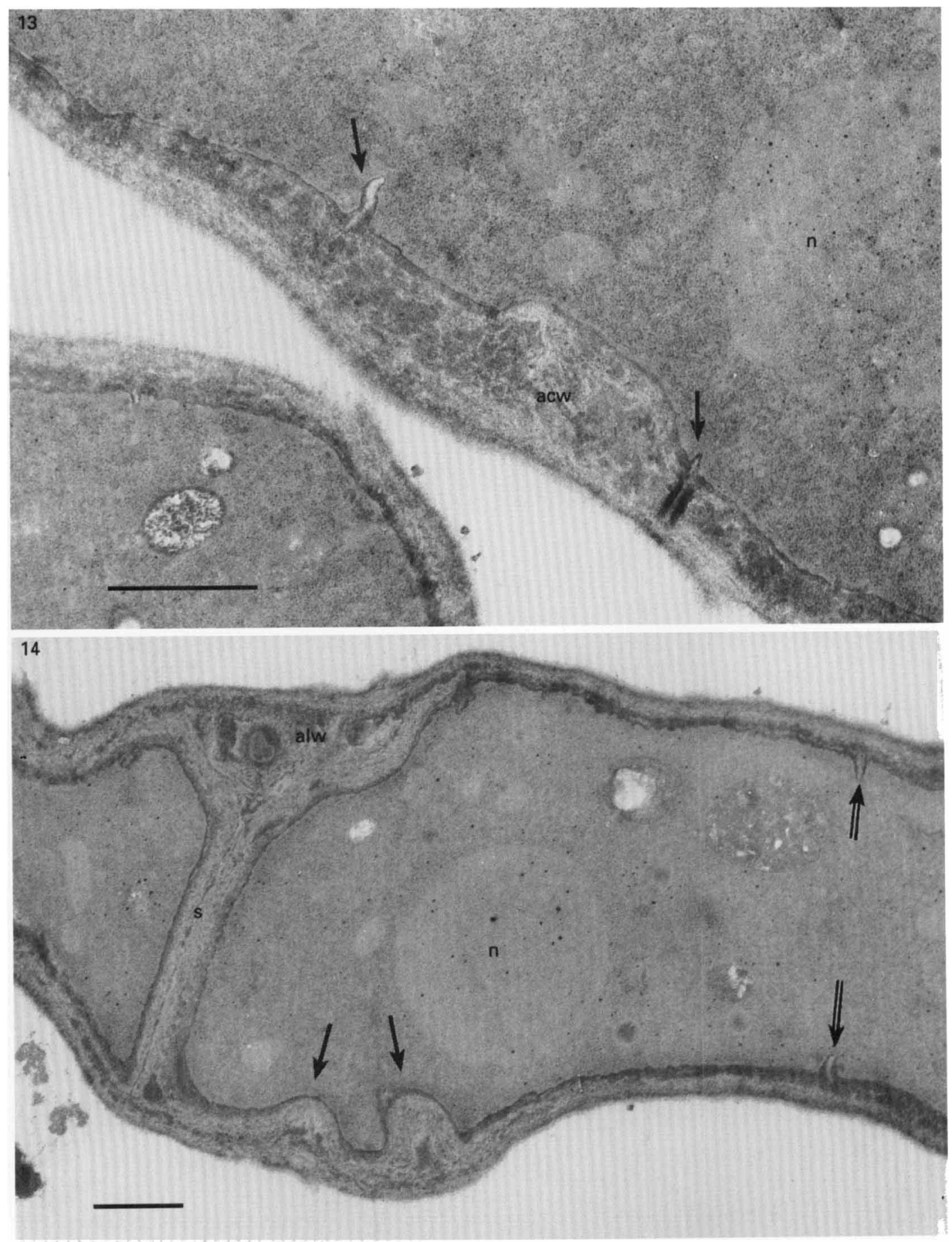

Fig. 13. Electron micrograph of an ultrathin section of a cell recovered from the effect of $C D$. At 10 min after removal of $\mathrm{CD}$, a primary septum was formed as an electron-transparent protrusion originating approximately at the cell equator. The micrograph shows the aberrant origin of two primary septa (arrows) growing out of a mass of thick aberrant wall material (acw). n, Nucleus. Bar, $1 \mu \mathrm{m}$.

Fig. 14. Electron micrograph of a longitudinal ultrathin section of a cell cultivated for $3.5 \mathrm{~h}$ in the medium after removal of CD. The thick septum (s), formed in the position of the aberrant lateral wall (alw), was not capable of separating daughter cells. Near the septum, thick wall protrusions are visible (arrows). After nuclear division a new primary septum is initiated in daughter cells (double arrows). $n$, Nucleus. Bar, $1 \mu \mathrm{m}$.

1/mid-1 (Chang et al., 1996), dmf-1/mid-1 (Sohrmann et al., 1996), cdc-16 and $c d c-15$ (Fankhauser et al., 1993, 1995), and $c d c-12$ (Chang et al., 1997). For example, the $\mathrm{dmf}-1 \mathrm{p}$ protein is located in the nucleus throughout interphase. As cells enter mitosis, dmf- $1 p$ forms a cortical ring at the position of the nucleus. This precedes 

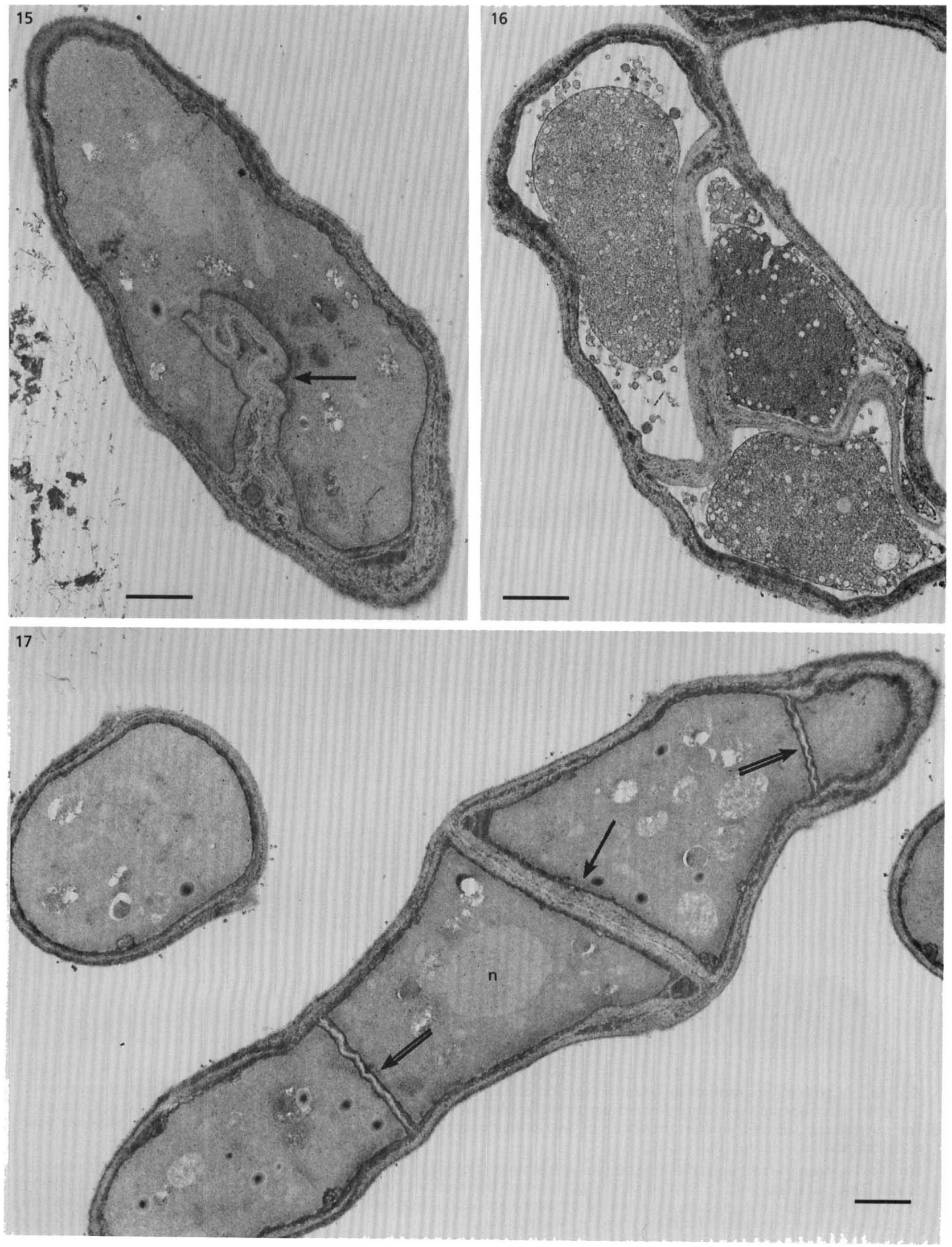

Figs 15, 16 and 17. For legends see facing page. 
formation of both the AR and the cdc- $15 \mathrm{p}$ ring. When septation is initiated, dmf- $1 \mathrm{p}$ is dephosporylated, the $\mathrm{dmf}-1 \mathrm{p}$ ring dissipates, and when the septum is completed and cells enter the next interphase, dmf- $1 \mathrm{p}$ is again localized in the nucleus (Sohrmann et al., 1996). The preexisting ARs in $S$. japonicus were removed and the formation of new ARs was blocked through inhibition of actin polymerization. However, the information on AR localization is 'remembered' by the cells for a few hours. It would be very interesting to know how these regulatory proteins behave in cells influenced by $\mathrm{CD}$ and after its removal.

In our study on $S$. japonicus, the actin gene was not mutated, only the polymerization of actin was inhibited by $\mathrm{CD}$. The formation of the AR (and the septum), and polar growth were blocked as long as $\mathrm{CD}$ was not removed and growth and cell proliferation were restored. In contrast, cells of $S$. pombe disrupted in the actin gene were more disturbed. Cells of the $c p s-8$ mutant of S. pombe (Ishiguro \& Kobayashi, 1996) having a mutation in the actin gene (Mertins \& Gallwitz, 1987) are affected even in permissive conditions; they form new septa slowly, but cell separation is blocked. When shifted to restrictive conditions the multinucleate cells rapidly separate at the previously formed septa but in the resulting cells nuclear division is often blocked and they suffer high lethality (Ishiguro \& Kobayashi, 1996, and references therein). It may be that the longitudinal actin microfilaments in temperaturesensitive mutants in actin gene are more disrupted than the actin contractile ring. The contractile ring is a complex of many components (Satterwhite \& Pollard, 1992; McCollum et al., 1995) in which actin plays a specific role. In spite of mutation in the $c p s-8$ gene, the AR remains more functional than it would if formed of simple actin microfilaments. Therefore, a cps-8 mutant creates septa, but polar growth is suppressed.

There is a difference between $S$. japonicus cells treated with $\mathrm{CD}$, which become binucleate, and $S$. pombe mutants blocked in $c d c-3,-4$ or -15 , which become multinucleate. Ishiguro \& Kobayashi (1996) showed also that the actin cps-8 mutant of $S$. pombe under restrictive conditions is also blocked in a binucleate state, similar to $S$. japonicus treated with CD. Moreover, mitotic spindles disappeared in the $c p s-8$ mutant under restrictive conditions. From this it may be deduced that F-actin may play some as yet unknown role in the nucleus, in which, however, the actin-associated protein products of $c d c-3,-4$ and -15 , the 'ring genes', do not function.

The 'purse string' model for cytokinesis, which proposes that cell cleavage occurs by contraction of a circumferential ring at the equator of the animal or budding yeast cell, was recently discussed and alternative mechanisms of cytokinesis were suggested (Fishkind \& Wang, 1995). Evidence for a pathway of ring formation in fission yeasts was recently described during analysis of cdc-12p localization in different cell types, suggesting that the site of ring assembly is initiated from a single point. Cells overexpressing cdc-12p contain incomplete rings, discontinuous on one side of the cdc12p staining spot (Chang et al., 1997). In our study, after removal of $\mathrm{CD}$, many $\mathrm{ARs}$ and septa (normal or aberrant) were observed in a short time. The colocalization of aberrant septa, cell wall protrusions and ARs or redundant actin bundles suggests that the deposition of septum material during septum formation is directly dependent on the localization and state of the AR. Our observation of these structures supports this new model in which ring assembly originates from a single point on the cortex (Chang et al., 1997).

The 'early septation mutants' $c d c-7, c d c-11, c d c-14$ and cdc-15 (Nurse et al., 1976; Fankhauser et al., 1995; McCollum et al., 1995) do not accumulate any deposits of septum material. In contrast, the 'late septation mutants' $c d c-3, c d c-8, \quad c d c-4$ and $c d c-12$ (Balasubramanian et al., 1992, 1994; McCollum et al., 1995; Chang et al., 1997) form both aberrant septa and irregular deposits of septum material (Streiblová et al., 1984; Mateos \& Domínguez, 1991). During the inhibition of actin polymeration by $C D$, deposition of septum material continues in the absence of actin cables and AR. This material is not as compact as the mature or the newly synthesized cell wall of wild-type cells. In contrast, it is similar to aberant cell wall which is formed in temperature-sensitve actin mutants of budding yeast (Gabriel \& Kopecká, 1995). In those cell walls a microfibrillar network of $(1 \rightarrow 3)-\beta$-glucan is mainly formed, but amorphous $(1 \rightarrow 6)-\beta$-glucan or mannoprotein is probably present at a low level. $(1 \rightarrow 3)$ $\beta$-Glucan synthase is present in the plasma membrane, while the $(1 \rightarrow 6)$ - $\beta$-glucan synthases or mannoprotein synthases are part of the secretory pathway (Shematek \& Cabib, 1980; Schekman \& Novick, 1982; Boone et al., 1990; Kopecká et al., 1995 ; Inoue et al., 1995, 1996; Cid et al., 1995; Klis et al., 1997; Cabib et al., 1997).

Fig. 15. Electron micrograph of an ultrathin section of a cell cultivated for $3.5 \mathrm{~h}$ in medium after removal of $C D$. It shows a misoriented loose course of wall protrusion (aberrant septation) (arrow), probably as a consequence of a redundant actin bundle capable of contraction, but incapable of accomplishing a continuous circular AR, and never partitioning the cytoplasm. Bar, $1 \mu \mathrm{m}$.

Fig. 16. Electron micrograph of an ultrathin section of a cell that was cultivated for $6 \mathrm{~h}$ in medium after removal of $C D$. The cell is separated by aberrant multiple septa into three compartments resulting from the formation of aberrant multiple ARs. Bar, $1 \mu \mathrm{m}$.

Fig. 17. Electron micrograph of a longitudinal ultrathin section of a cell cultivated for $3.5 \mathrm{~h}$ in medium after removal of CD. A thick aberrant septum, formed soon after removal of CD (arrow), is seen. It did not enable separation of the daughter cells. The daughter cells are already forming normal septa (double arrows). $n$, Nucleus. Bar, $1 \mu \mathrm{m}$. 
Actin is also involved in directing cell wall deposition at the growing region of the cell (Kanbe et al., 1993; Welch et al., 1994). We suggest that in actin mutants or when the polymerization of actin microfilaments is inhibited, the targeted transport of components of the amorphous matrix is destroyed. Therefore those components are present at a low level.

The cdc- $4 p$ protein (a putative myosin light chain) is important in ring formation (McCollum et al., 1995) but it may also be required in a later step in ring formation (Chang et al., 1997). In this context an interesting finding is that the csmA gene of Aspergillus nidulans encodes an N-terminal myosin motor-like domain outside the chitin synthase conserved domain, i.e. the unconventional myosin fused to a metabolic enzyme. This suggests that localization of chitin synthase may be guided by association with cytoskeletal structures (Fujiwara et al., 1997). Although chitin, which plays a role in separation of budding yeasts (Shaw et al., 1991), has been observed in only small quantities in $S$. pombe (Sietsma \& Wessels, 1990), it may play a similar role in septation in both organisms.

Relationships between other cell wall materials and the cytoskeleton may also be found in addition to that shown for myosin and chitin synthase (Fujiwara et al., 1997). A relationship of actin patches to the formation of 'cell surfaces' has been suggested since the first papers on the yeast cytoskeleton appeared (Adams \& Pringle, 1984; Kilmartin \& Adams, 1984; Marks \& Hyams, 1985; Marks et al., 1986), but their detailed characteristics and function are not yet completely understood in spite of a considerable number of published reports (e.g. Kanbe et al., 1989, 1993; Kobori et al., 1989, 1994; Akashi et al., 1994; Mulholland et al., 1994; Waddle et al., 1996; Doyle \& Botstein, 1996). Although actin patches are based on F-actin (Wulf et al., 1979; Adams \& Pringle, 1984; Kilmartin \& Adams, 1984), their resistance to $C D$ also indicates a different role from that of actin microfilaments in actin cables or the AR. After application of $\mathrm{CD}$, actin patches in $S$. japonicus cells were localized in a dense band, along the cell equatorial plane. This dense band of actin patches was co-localized with a wide band of aberrant septum material. The colocalization of actin patches and newly synthesized cell wall (septum) material on atypical sites on the lateral cell wall again indicates a close relationship between actin patches and cell wall synthesis.

Study of protoplasts of $S$. pombe after CD treatment showed a dependence of cell wall regeneration on actin (Kobori et al., 1989). Protoplasts of S. japonicus after $\mathrm{CD}$ treatment also did not make a complete cell wall but formed only a fibrillar network. During its synthesis actin patches were detected. This problem is now being studied in detail.

\section{AKNOWLEDGEMENTS}

We wish to thank Mrs V. Ramíková, Mrs D. Hradilová, Mrs J. Drápalová and Ing. L. Ilkovics for their technical assistance.
This work was supported by the Grant Agency of the Czech Republic, Grants G204/93/0667 and G204/97/1150.

\section{REFERENCES}

Adams, A. E. M. \& Pringle, J. R. (1984). Relationship of actin and tubulin distribution to bud growth in wild-type and morphogenetic mutant Saccharomyces cerevisiae. J Cell Biol 98, 934-943.

Akashi, T., Kanbe, T. \& Tanaka, K. (1994). The role of the actin cytoskeleton in the polarized growth of the germ tube in Candida albicans. Microbiology 140, 271-280.

Alfa, C. E. \& Hyams, J. S. (1990). Distribution of tubulin and actin through the cell division cycle of the fission yeast Schizosaccharomyces japonicus var. versatilis: a comparison with Schizosaccharomyces pombe. J Cell Sci 96, 71-77.

Balasubramanian, M. K., Helfman, D. M. \& Hemmingsen, S. M. (1992). A new tropomyosin essential for cytokinesis in the fission yeast $S$. pombe. Nature 360, 84-87.

Balasubramanian, M. K., Hirani, B. R., Burke, J. D. \& Gould, K. L. (1994). The Schizosaccharomyces pombe cdc-3 gene encodes a profilin essential for cytokinesis. J Cell Biol 125, 1289-1301.

Barja, F. \& Turian, G. (1994). Cytochalasin B-sensitive actinmediated nuclear RNA export in germinating conidia of Neurospora crassa. Cell Biol Int 18, 903-906.

Boone, Ch., Sommer, S. S., Hensel, A. \& Bussey, H. (1990). Yeast $K R E$ genes provide evidence for a pathway of cell wall $\beta$-glucan assembly. J Cell Biol 110, 1833-1843.

Cabib, E., Drgon̆, T., Drgoňová, J., Ford, R. A. \& Kollár, R. (1997). The yeast cell wall, a dynamic structure engaged in growth and morphogenesis. Biochem Soc Trans 25, 200-204.

Chang, F. \& Nurse, P. (1996). How fission yeast fission in the middle. Cell 84, 191-194

Chang, F., Woollard, A. \& Nurse, P. (1996). Identification and characterization of fission yeast mutants defective in contractile actin ring assembly. $J$ Cell Sci 109, 131-142.

Chang, F., Drubin, D. \& Nurse, P. (1997). cdc12p, a protein required for cytokinesis in fission yeast, is a component of the cell division ring and interacts with profilin. J Cell Biol 137, 169-182.

Cid, V. J., Durán, A., Del Rey, F., Snyder, M. P., Nombela, C. \& Sánchez, M. (1995). Molecular basis of cell integrity and morphogenesis in Saccharomyces cerevisiae. Microbiol Rev 59, 345-386.

Doyle, T. \& Botstein, D. (1996). Movement of cortical actin cytoskeleton visualized in vivo. Proc Natl Acad Sci USA 93, 3886-3891.

Fankhauser, Ch. \& Simanis, V. (1994). The cdc7 protein kinase: a dosage-dependent regulator of septum formation in fission yeast. EMBO J 13, 3011-3019.

Fankhauser, Ch., Marks, J., Reymond, A. \& Simanis, V. (1993). The $S$. pombe $c d c 16$ gene is required both for maintenance of $\mathrm{p} 34^{c a c 2}$ kinase activity and regulation of septum formation: a link between mitosis and cytokinesis? EMBO J 12, 2697-2704.

Fankhauser, Ch., Reymond, A., Cerutti, L., Utzig, S., Hofmann, K. \& Simanis, v. (1995). The $S$. pombe $c d c 15$ gene is a key element in the reorganization of F-actin at mitosis. Cell 82, 435-444.

Fishkind, D. J. \& Wang, Y. (1995). New horizons for cytokinesis. Curr Opin Cell Biol 7, 23-31.

Fujiwara, M., Horiuchi, H., Ohta, A. \& Takagi, M. (1997). A novel fungal gene encoding chitin synthase with a myosin motor-like domain. Biochem Biophys Res Commun 236, 75-78.

Gabriel, M. \& Kopecka, M. (1995). Disruption of the actin 
cytoskeleton in budding yeast results in formation of an aberrant cell wall. Microbiology 141, 891-899.

Glover, D. M., Ohkura, H. \& Tavares, A. (1996). Polo kinase: the choreographer of the mitotic stage? J Cell Biol 135, 1681-1684.

Hasek, J., Svobodová, J. \& Streiblová, E. (1986). Immunofluorescence of the microtubular skeleton in growing and drug treated yeast protoplasts. Eur J Cell Biol 41, 150-156.

Inoue, S. B., Takewaki, N., Takasuka, T., Mio, T., Adachi, M., Fujii, Y., Miyamoto, C., Arisawa, M., Furuichi, Y. \& Watanabe, T. (1995). Characterization and gene cloning of $1,3-\beta$-D-glucan synthase from Saccharomyces cerevisiae. Eur J Biochem 231, 845-854.

Inoue, S. B., Qadota, H., Arisawa, M., Anraku, Y., Watanabe, T. \& Ohya, Y. (1996). Signaling toward yeast 1,3- $\beta$-glucan synthesis. Cell Struct Funct 21, 395-402.

Ishiguro, J. \& Kobayashi, W. (1996). An actin point-mutation neighboring the 'hydrophobic plug' causes defects in the maintenance of cell polarity and septum organization in the fission yeast Schizosaccharomyces pombe. FEBS Lett 392, 237-241.

Kanbe, T., Kobayashi, I. \& Tanaka, K. (1989). Dynamics of cytoplasmic organelles in the cell cycle of the fission yeast Schizosaccharomyces pombe: three-dimensional reconstruction from serial sections. J Cell Sci 94, 647-656.

Kanbe, T., Akashi, T. \& Tanaka, K. (1993). The effect of cytochalasin A on actin distribution in the fission yeast Schizosaccharomyces pombe studied by fluorescence and electron microscopy. Protoplasma 176, 24-32.

Kanbe, T., Akashi, T. \& Tanaka, K. (1994). Changes in the distribution of F-actin in the fission yeast Schizosaccharomyces pombe by arresting growth in distilled water: correlative studies with fluorescence and electron microscopy. J Electron Microsc $43,20-24$.

Kilmartin, J. V. \& Adams, A. E. M. (1984). Structural rearrangements of tubulin and actin during the cell cycle of the yeast Saccharomyces. J Cell Biol 98, 922-933.

Klis, F. M., Caro, L. H. P., Vossen, J. H., Kapteyn, J. C., Ram, A. F. J., Montijn, R. C., Van Berkel, M. A. A. \& Van Den Ende, H. (1997). Identification and characterization of a major building block in the cell wall of Saccharomyces cerevisiae. Biochem Soc Trans 25, 856-860.

Kobori, H., Yamada, N., Taki, A. \& Osumi, M. (1989). Actin is associated with the formation of the cell wall in reverting protoplasts of the fission yeast Schizosaccharomyces pombe. $J$ Cell Sci 94, 635-646.

Kobori, H., Sato, M. \& Osumi, M. (1992). Relationship of actin organization to growth in the two forms of the dimorphic yeast Candida tropicalis. Protoplasma 167, 193-204

Kobori, H., Toda, T., Yaguchi, H., Toya, M., Yanagida, M. \& Osumi, M. (1994). Fission yeast protein kinase $C$ gene homologues are required for protoplast regeneration: a functional link between cell wall formation and cell shape control. J Cell Sci 107, 1131-1136.

Kopecká, M., Fleet, G. H. \& Phaff, H. J. (1995). Ultrastructure of the cell wall of Schizosaccharomyces pombe following treatment with various glucanases. J Struct Biol 114, 140-152.

Kumada, K., Su, S., Yanagida, M. \& Toda, T. (1995). Fission yeast TPR-family protein nuc2 is required for G1-arrest upon nitrogen starvation and is an inhibitor of septum formation. J Cell Sci 108, 895-905.

McCollum, D., Balasubramanian, M. K., Pelcher, L. E., Hemmingsen, S. M. \& Gould, K. L. (1995). Schizosaccharomyces pombe $c d c 4+$ gene encodes a novel EF-hand protein essential for cytokinesis. J Cell Biol 130, 651-660.
McCollum, D., Feoktistova, A., Morphew, M., Balasubramanian, M. \& Gould, K. L. (1996). The Schizosaccharomyces pombe actinrelated protein, Arp3, is a component of the cortical actin cytoskeleton and interacts with profilin. $E M B O J 15,6438-6446$.

Marks, J. \& Hyams, J. S. (1985). Localization of F-actin through the cell division cycle of Schizosaccharomyces pombe. Eur J Cell Biol 39, 27-32.

Marks, J., Hagan, I. M. \& Hyams, J. S. (1986). Growth polarity and cytokinesis in fission yeast : the role of the cytoskeleton. J Cell Sci (Suppl.) 5, 229-241

Marks, J., Hagan, I. M. \& Hyams, J. S. (1987). Spatial association of F-actin with growth polarity and septation in the fission yeast Schizosaccharomyces pombe. In Spatial Organization in Eukaryotic Microbes, pp. 119-135. Edited by R. K. Poole \& A. P. J. Trinci. Oxford: IRL Press.

Marks, J., Fankhauser, C. \& Simanis, V. (1992). Genetic interactions in the control of septation in Schizosaccharomyces pombe. $J$ Cell Sci 101, 801-808

Mateos, P. \& Domínguez, A. (1991). Ultrastructure and cell wall composition in cell division cycle mutants of Schizosaccharomyces pombe deficient in septum formation. Antonie Leeuwenhoek 59, 155-165

Mertins, P. \& Gallwitz, D. (1987). A single intronless actin gene in the fission yeast Schizosaccharomyces pombe; nucleotide sequence and transcripts formed in homologous and heterologous yeast. Nucleic Acids Res 15, 7369-7379.

Minet, M., Nurse, P., Thuriaux, P. \& Mitchison, J. M. (1979). Uncontrolled septation in cell division cycle mutant of the fission yeast Schizosaccharomyces pombe. J Bacteriol 137, 440-446.

Mulholland, J., Preuss, D., Moon, A., Drubin, D. \& Botstein, D. (1994). Ultrastructure of the yeast actin cytoskeleton and its association with the plasma membrane. J Cell Biol 125, 381-391.

Novick, P. \& Botstein, D. (1985). Phenotypic analysis of temperature sensitive yeast actin mutants. Cell 40, 405-416.

Nurse, P., Thuriaux, P. \& Nasmyth, K. (1976). Genetic control of the cell cycle in the fission yeast Schizosaccharomyces pombe. Mol Gen Genet 146, 167-178.

Ohkura, H., Hagan, J. M. \& Glover, D. M. (1995). The conserved Schizosaccharomyces pombe kinase plo 1 , required to form a bipolar spindle, the actin ring, and septum, can drive septum formation in G(1) and G(2) cells. Genes Dev 9, 1059-1073.

Pringle, J. R. (1991). Staining of bud scars and other cell wall chitin with calcofluor. Methods Enzymol 194, 732-735.

Pringle, J. R., Preston, R. A., Adams, A. E. M., Stearns, T., Drubin, D. G, Haarer, B. K. \& Jones, W. E. (1989). Fluorescence microscopy methods for yeasts. Methods Cell Biol 31, 357-435.

Robinow, C. F. \& Hyams, J. S. (1989). General cytology of fission yeast. In The Molecular Biology of the Fission Yeast, pp. 273-331. Edited by A. Nasim, P. Young \& B. F. Johnson. New York: Academic Press.

Sampath, P. \& Pollard, T. D. (1991). Effect of cytochalasin, phalloidin, and $\mathrm{pH}$ on the elongation of actin filaments. Biochemistry 30, 1973-1980.

Satterwhite, L. L. \& Pollard, T. D. (1992). Cytokinesis. Curr Opin Cell Biol 4, 43-52.

Schekman, R. \& Novick, P. (1982). The secretory process and yeast cell-surface assembly. In The Molecular Biology of the Yeast Saccharomyces, vol. 2, Metabolism and Gene Expression, pp. 361-398. Edited by J. N. Strathern, E. W. Jones \& J. R. Broach. Cold Spring Harbor, NY: Cold Spring Harbor Laboratory.

Schmidt, S., Sohrmann, M., Hofmann, K., Woollard, A. \& Simanis, 
v. (1997). The spg1p GTPase is an essential, dosage-dependent inducer of septum formation in Schizosaccharomyces pombe. Genes Dev 11, 1519-1534.

Shaw, J. A., Mol, P. C., Bowers, B., Silverman, S. J., Valdivieso, M. H., Durán, A. \& Cabib, E. (1991). The function of chitin synthases 2 and 3 in the Saccharomyces cerevisiae cell cycle. J Cell Biol 114, 111-123.

Shematek, E. M. \& Cabib, E. (1980). Biosynthesis of the yeast cell wall. II. Regulation of $\beta-(1 \rightarrow 3)$ glucan synthetase by ATP and GTP. J Biol Chem 255, 895-902.

Sietsma, J. H. \& Wessels, J. G. H. (1990). The occurrence of glucosaminoglycan in the wall of Schizosaccharomyces pombe. $J$ Gen Microbiol 136, 2261-2265.

Simanis, V. (1995). The control of septum formation and cytokinesis in fission yeast. Semin Cell Biol 6, 79-87.

Sipiczki, M., Grallert, B. \& Miklos, I. (1993). Mycelial and syncytial growth in Schizosaccharomyces pombe induced by novel septation mutations. J Cell Sci 104, 485-493

Sohrmann, M., Fankhauser, Ch., Brodbeck, C. \& Simanis, V. (1996). The $d m f 1 / m i d 1$ gene is essential for correct positioning of the division septum in fission yeast. Genes Dev 10, 2707-2719.

Solomon, F. (1991). Analyses of the cytoskeleton in Saccharomyces cerevisiae. Annu Rev Cell Biol 7, 633-662
Streiblová, E., HaŠk, J. \& Jelke, E. (1984). Septum pattern in ts mutants of Schizosaccharomyces pombe defective in genes $c d c 3$, $c d c 4, c d c 8$ and $c d c$ 12. J Cell Sci 69, 47-65

Svoboda, A., Băhler, J. \& Kohli, J. (1995). Microtubule-driven nuclear movements and linear elements as meiosis-specific characteristics of the fission yeasts Schizosaccharomyces versatilis and Schizosaccharomyces pombe. Chromosoma 104, 203-214.

Waddle, J. A., Karpova, T. S., Waterson, R. H. \& Cooper, J. A. (1996). Movement of cortical actin patches in yeast. J Cell Biol $132,861-870$.

Welch, M. D., Holtzman, D. A. \& Drubin, D. G. (1994). The yeast actin cytoskeleton. Curr Opin Cell Biol 6, 110-119.

Woods, A., Sherwin, T., Sasse, R., McRae, T. H., Baines, A. J. \& Gull, K. (1989). Definition of individual components within the cytoskeleton of Trypanosoma brucei by a library of monoclonal antibodies. J Cell Sci 93, 491-500.

Wulf, E., Deboben, A., Bautz, F. A., Faulstich, H. \& Wieland, T. (1979). Fluorescent phallotoxin, a tool for the visualisation of cellular actin. Proc Natl Acad Sci USA 76, 4498-4502.

Received 26 August 1997; revised 23 February 1998; accepted 16 March 1998. 